\title{
Utility of Cord Blood Albumin as a Predictors of Significant Neonatal Hyperbilirubinemia in Healthy Term Neonate.
}

\author{
Rajkumar M. Meshram ${ }^{1}$, Saira Merchant ${ }^{2}$, Sartajbegam N. Pathan ${ }^{3}$ \\ ${ }^{1}$ Associate Professor, Department of Paediatrics, Government Medical College, Nagpur, Maharashtra, India, ${ }^{2}$ Professor, Department of Paediatrics, Government Medical \\ College, Nagpur, Maharashtra, India, ${ }^{3} \mathrm{PG}$ Student, Department of Paediatrics, Government Medical College, Nagpur, Maharashtra, India.
}

\section{Abstract}

Background: Approximately $60 \%$ of term and $80 \%$ of preterm neonates develop jaundice in first week of life and significant neonatal hyperbilirubinemia occurs in 3-5\% of healthy term neonates. Objective: To assess the cord blood albumin level as a tool to screen the risk of development of subsequent significant neonatal hyperbilirubinemia in term neonate. Subjects and Methods: A prospective observational study was conducted over a period of 2 years on 1040 healthy term neonates. Demographic profile, relevant maternal and neonatal information were recorded. Measurement of cord blood albumin, blood group/Rh typing and serum bilirubin at the end of $24 \& 72$ hours was done to predict significant hyperbilirubinemia. Results: A total of 1040 healthy term neonates were enrolled with male to female ratio of $1.4: 1$. 120 neonates had developed significant hyperbilirubinemia and required phototherapy while 2 of them did not respond to phototherapy and needed exchange transfusion. Out of 245(23.55\%) neonates with low cord albumin level $(<2.8 \mathrm{gm} / \mathrm{dl}), 104(42.44 \%)$ neonates had significant hyperbilirubinemia at the end of 24 hours with sensitivity $86.67 \%$, specificity $84.67 \%$, positive predictive value $42.45 \%$ and negative predictive value $97.66 \%$. While $105(42.85 \%)$ neonates had significant jaundice at the end of 72 hours with cord blood albumin $<2.8$ gm/dl with sensitivity $87.50 \%$, specificity $84.78 \%$ positive predictive value- $42.86 \%$ and negative predictive value- $98.11 \%$. Conclusion: Neonates with cord blood albumin level more than $2.8 \mathrm{gm} / \mathrm{dl}$ can be safely discharged early whereas neonates with albumin levels $<2.8 \mathrm{~g} / \mathrm{dl}$ will need close follow up to check for development of significant jaundice. Hence cord blood albumin levels help to determine and predict the possibility of significant jaundice among healthy term neonates.

Keywords: Cord blood albumin, Icterus, Jaundice, Significant hyperbilirubinemia.

Corresponding Author: Dr. Saira Merchant, Professor, Department of Pediatrics, Government medical College, Nagpur, Maharashtra (India).

Received: December 2018

Accepted: January 2019

\section{Introduction}

Jaundice is the visible manifestation of elevated serum bilirubin in skin and sclera. Thousands years ago, it was described in Chinese literature and in the 18th century Junker first differentiated between true jaundice and the yellowish tinge observed in many neonates. ${ }^{[1,2]}$

Approximately $60 \%$ of term and $80 \%$ of preterm neonates develop jaundice in first week of life and significant neonatal hyperbilirubinemia is a cause of concern for the parents and pediatricians as well and it occurs in $3-5 \%$ of healthy term infants. ${ }^{[3,4]}$

Early discharge of healthy term newborn after delivery has become a common practice because of medical, social and economic reasons. ${ }^{[5]}$ The most common cause for readmission during the early neonatal period is hyperbilirubinemia. The American Academy of Pediatrics (AAP) recommends that newborn discharged within 48 hours should have a follow up visit after 2-3 days to detect significant jaundice and other problems. ${ }^{[6]}$ In developing countries like India, this recommendation is not practical due to limited follow up facilities.

Liver is the site of synthesis of albumin appears at approximately the 7-8 weeks in the human fetus and it increases in inverse proportion to that of $\alpha$-fetoprotein, which is the dominant fetus protein. It binds to unconjugated bilirubin and helps in the transport. Around $8.5 \mathrm{mg}$ of bilirubin will bind tightly to 1 gram of albumin. Free bilirubin is anticipated when the bilirubin to albumin ratio is $>0.8$. Although bilirubin may have a physiologic role as an antioxidant but elevations of unconjugated bilirubin are potentially neurotoxic.

The concept of prediction of jaundice offers an attractive option to pick up babies at risk of developing significant neonatal hyperbilirubinemia. Physical examination is not a reliable measure of the serum bilirubin. Under these circumstances it would be desirable to predict the risk of neonatal hyperbilirubinemia in order to implement early treatment and thereby minimize the risk of bilirubin dependent brain damage. By predicting the neonates likely to develop significant neonatal jaundice early at birth, we can design and implement the follow-up programme in these high risk group effectively. 
Hence, the purpose of the study is to verify whether the bilirubin and albumin levels in cord blood could predict the subsequent development of significant hyperbilirubinemia requiring interventions like phototherapy or exchange transfusion.

\section{Subjects and Methods}

This prospective observational study was undertaken at neonatology unit of one of the largest tertiary care teaching government referral hospital of central India over a period of 2 years from October 2015 to September 2017. The study was approved by Institutional Ethics Committee. After explaining the nature and conduct of study in local language and written informed consent from parents or care giver, healthy term neonates of either sex, delivered vaginally or caesarean with birth weight more than $2.5 \mathrm{~kg}$ and Apgar score $\geq 7$ at first and fifth minute were enrolled in the study. Neonates with $\mathrm{ABO} / \mathrm{Rh}$ incompatibility, prematurity, cephalhematoma, birth trauma, and meconium stained amniotic fluid, early onset sepsis and major congenital malformations were excluded from the study. Information obtained during the study was kept confidential. Sample size was calculated by considering prevalence of development of jaundice in term neonate $(60 \%)$ with precision of $5 \%$ and confidence level at $95 \%$ was 1.96. A 1040 healthy term neonate who fulfilled the inclusion criteria were recruited for the study. Demographic profile, relevant maternal and neonatal information were recorded in specially designed structured proforma for this study. Gestational age was assessed by New Ballard score. ${ }^{[7]}$ All the neonates were examined daily for feeding pattern, development of icterus, passage of adequate stool \& urine, lethargy and other dangerous signs. All the babies were followed up daily for first 3 postnatal days and babies were assessed daily for neonatal hyperbilirubinemia and its severity by Kramer's staging scale. ${ }^{[8]}$

At the end of 24 hours and 72 hours of life all neonates subjected to serum bilirubin estimation and blood group and Rh typing.

\section{Laboratory Procedures: \\ Cord Blood Albumin:}

After delivery of the neonate, the umbilical cord was double clamped and transected within 10 seconds. As soon as the neonate was removed from the operative field, cord blood was collected as follows. The placental side part of the umbilical cord was held straight at a slight angle downward. After identification of a suitable puncture site, the cord was cleaned, the umbilical vein was punctured with sterile syringe and approximately $3 \mathrm{ml}$ blood was withdrawn and then put in plain tube to be separated by centrifugation. Separated serum was tested for albumin. Cord albumin was assessed by using BCG method on Beckman automated analyzer. Cord blood albumin of $2.8 \mathrm{gm} / \mathrm{dl}$ was considered as cutoff value for the present study.

\section{Total Serum Bilirubin:}

With all aseptic precaution at the end of 24 hours and 72 hours of life, $2 \mathrm{ml}$ of venous blood sample was collected for bilirubin estimation. Serum bilirubin estimation was done by Diazotized sulfanilic acid test. As per the National Neonatology Forum and American Academy of Paediatrics guidelines, total serum bilirubin $>10 \mathrm{mg} / \mathrm{dl}$ at the end of 24 hours of life and $\geq 17 \mathrm{mg} / \mathrm{dl}$ at the end of 72 hours of life were considered as significant hyperbilirubinemia. ${ }^{[6]}$

Those neonates who developed significant hyperbilirubinemia, they were treated with phototherapy. Exchange transfusion was done in neonates, whose hyperbilirubinemia did not respond to phototherapy and crossed the recommended level.

Blood group estimation was done by using commercial available antisera kit.

\section{Statistical Analysis:}

The data was entered into Microsoft excel sheet and analysis was done by using software STATA version 14 with " $t$ " test, chi-squre test. Sensitivity, specificity, negative and positive predictive value of test was calculated.

\section{Results}

Table 1: Baseline characteristics of study population

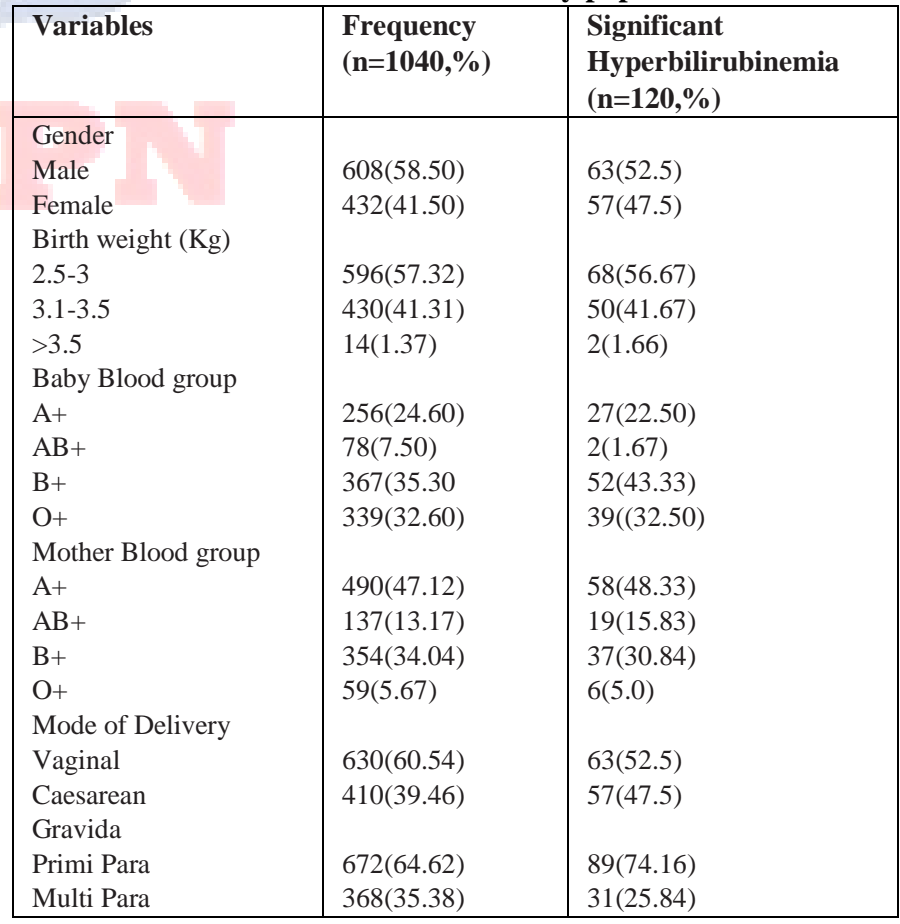

In present study, a total of 1040 term neonates were enrolled. Out of this $608(58.50 \%)$ were male and $432(41.50 \%)$ were female. $64.62 \%$ mothers were primipara and $60.54 \%$ neonate were born by vaginal route. $47.12 \%$ 
mother had A+ blood group followed by B+ in $34.04 \%$ while commonest blood group of baby was $(35.30 \%) \mathrm{B}+$ followed by $\mathrm{O}+$ in $32.60 \%$. Most of the neonates had fallen into birth weight $2.5-3 \mathrm{~kg}$ group [Table 1].

Clinically, in majority of cases $790(57.97 \%)$ jaundice was seen over face followed by chest and upper abdomen in $152(14.64 \%)$ at the end of 24 hours of life while in $112(10.77 \%)$ jaundice was seen over arms \& lower legs, and in $2(0.19 \%)$ neonates jaundice extended up to palms and soles at the end of 72 hours of life [Figure 1]. 120 neonates had developed significant hyperbilirubinemia and required phototherapy while 2 of them did not respond to phototherapy and needed exchange transfusion [Figure 2].

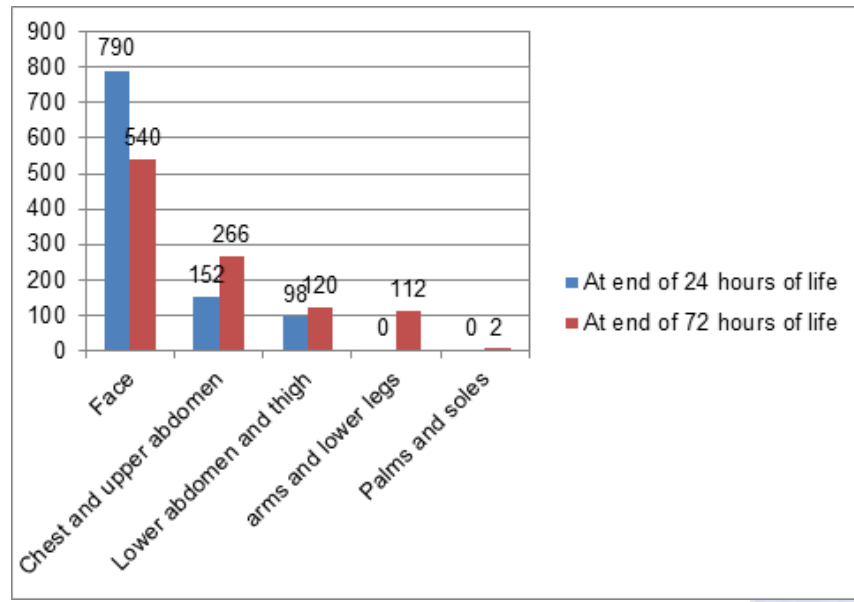

Figure 1: Distribution of cases according to Kramer staging.

\section{Significant Hyperbilirubinemia}

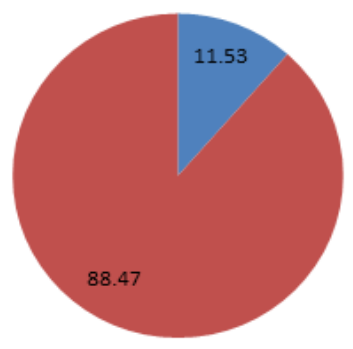

Figure 2: Prevalance of significant hyperbilirubinemia in study

Table 2: Correlation between cord blood albumin and serum bilirubin at the end of 24 hours.

\begin{tabular}{|l|l|l|l|l|}
\hline \multirow{2}{*}{$\begin{array}{l}\text { Cord } \\
\text { blood } \\
\text { albumin }\end{array}$} & \multicolumn{2}{|l|}{$\begin{array}{l}\text { Total serum bilirubin at the } \\
\text { end of 24 hours }\end{array}$} & \multirow{2}{*}{$\begin{array}{l}\text { Total } \\
(\mathbf{n = 1 0 4 0})\end{array}$} & \multirow{2}{*}{ P-value } \\
\cline { 2 - 3 } & $>\mathbf{1 0 m g} / \mathbf{d l}$ & $<\mathbf{1 0 m g} / \mathbf{d l}$ & & \\
\hline$<2.8 \mathrm{gm} / \mathrm{dl}$ & $104(42.44 \%)$ & $141(57.56 \%)$ & $245(23.55 \%)$ & \\
\hline$\geq 2.8 \mathrm{gm} / \mathrm{dl}$ & $16(2.02 \%)$ & $779(97.98 \%)$ & $795(76.45 \%)$ & $<0.001$ \\
\hline
\end{tabular}

Out of $795(76.45 \%)$ neonate with cord blood albumin level $>2.8 \mathrm{gm} / \mathrm{dl}, 16(2.02 \%)$ had bilirubin more than $10 \mathrm{mg} / \mathrm{dl}$ at the end of 24 hours while out of $245(23.55 \%)$ neonate with low cord albumin level $(<2.8 \mathrm{gm} / \mathrm{dl}), 104(42.44 \%)$ neonate had total serum bilirubin more than $10 \mathrm{mg} / \mathrm{dl}$ at the end of 24 hours with sensitivity $86.67 \%$, specificity $84.67 \%$, positive predictive value $42.45 \%$ and negative predictive value $97.66 \%$. Thus neonates with low cord albumin had increased occurrence of significant hyperbilirubinemia at the end of 24 hours and it was statistically significant. [Table 2].

Table 3: Correlation between cord blood albumin and serum bilirubin at the end of $\mathbf{7 2}$ hours.

\begin{tabular}{|l|l|l|l|l|}
\hline \multirow{2}{*}{$\begin{array}{l}\text { Cord } \\
\text { blood } \\
\text { albumin }\end{array}$} & \multicolumn{2}{|l|}{$\begin{array}{l}\text { Total serum bilirubin at the } \\
\text { end of 72 hours }\end{array}$} & \multirow{2}{*}{$\begin{array}{l}\text { Total } \\
(\mathbf{n = 1 0 4 0})\end{array}$} & P-value \\
\cline { 2 - 4 } & $>\mathbf{1 7} \mathbf{m g} / \mathbf{d l}$ & $<\mathbf{1 7 m g} / \mathbf{d l}$ & & \\
\hline$<2.8 \mathrm{gm} / \mathrm{dl}$ & $105(42.85 \%)$ & $140(57.15 \%)$ & $245(23.55 \%)$ & \multirow{2}{*}{$<0.001$} \\
\hline$\geq 2.8 \mathrm{gm} / \mathrm{dl}$ & $15(1.89 \%)$ & $780(98.11 \%)$ & $795(76.45 \%)$ & \\
\hline
\end{tabular}

A $15(1.89 \%)$ neonates had bilirubin $>17 \mathrm{mg} / \mathrm{dl}$ at the end of 72 hours with cord blood albumin $\geq 2.8 \mathrm{gm} / \mathrm{dl}$ while 105 $(42.85 \%)$ neonates were observed with serum bilirubin $>17 \mathrm{mg} / \mathrm{dl}$ at the end of 72 hours with cord blood albumin $<2.8 \mathrm{gm} / \mathrm{dl}$ with sensitivity $87.50 \%$, specificity $84.78 \%$ positive predictive value- $42.86 \%$ and negative predictive value $-98.11 \%$ and this difference is statistically significant. [Table 3].

\section{Discussion}

Neonates have an immature liver function resulting into decreased production and synthesis of proteins as compared to adults. Albumin is the carrier protein for transport of unconjugated bilirubin to get conjugated and excrete in urine and stool. Low albumin and two to three fold more production of bilirubin in neonate versus adult results into more unconjugated bilirubin in circulation. Excess amount of unconjugated (free) bilirubin causes brain damage due to neurotoxic effect of free bilirubin and this is preventable and treatable if detect early. The current recommended guidelines are to discharge early and follow up of term neonates but this is difficult in countries with limited follow up facilities. The concept of prediction of jaundice offers an attractive option to pick up babies at risk of neonatal hyperbilirubinemia. So the present study was planned to assess the cord blood albumin level as a tool to screen the risk of development of subsequent significant neonatal hyperbilirubinemia in term neonate.

In present study, out of 1040 neonates, $58.50 \%$ were males and $41.50 \%$ were females and there were no statistical significance between development of significant hyperbilirubinemia and gender. Similar types of sex distribution are reported in various studies while few studies document that females outnumbered the males..$^{[9-11]}$ Amongst 630 neonates of vaginally born, 63 had significant hyperbilirubinemia while out of 410 caesarean delivered, 57 had significant jaundice and difference between mode of delivery and development of significant hyperbilirubinemia was insignificant. This was in correlation with results of Sun 
G et al and Sahu et al. ${ }^{[12,13]}$ Similar to Aiyappa et al and Pradhan et al, ${ }^{[14]}$ it was noted that neonates born with lower birth weight had a higher chance of developing significant icterus. Distribution of blood group of mothers and neonates in study population is similar to observation noted by Taksande et $\mathrm{al}^{\left[{ }^{[15]}\right.}$ and there were no significant difference between developments of significant hyperbilirubinemia and blood group of mothers/babies.

In present study, 120 neonates developed significant hyperbilirubinemia, giving prevalence of $11.53 \%$ which was similar to Pradhan et al, ${ }^{[14]}$ and Randev et al ${ }^{[16]}$ while higher prevalence for development of significant jaundice (27.34\%) were reported by Gupta $S$ et $a l,{ }^{[17]}$ and lower incidence (9.5\%) by Taksande et al and $10 \%$ by Kumar S et al. All neonates with significant hyperbilirubinemia were treated with phototherapy, two of them did not respond and exchange transfusion was performed on them. It was noted that out of 245(23.55\%)neonate with low cord albumin level $(<2.8 \mathrm{gm} / \mathrm{dl}), \quad 104(42.44 \%)$ neonate had significant hyperbilirubinemia at the end of 24 hours with sensitivity $86.67 \%$, specificity $84.67 \%$, positive predictive value $42.45 \%$ and negative predictive value $97.66 \%$, while 105 $(42.85 \%)$ neonates were observed with serum bilirubin $>17 \mathrm{mg} / \mathrm{dl}$ at the end of 72 hours with sensitivity $87.50 \%$, specificity $84.78 \%$ positive predictive Value- $42.86 \%$ and negative predictive Value- $98.11 \%$ and this difference was statistically significant. Neonate with low cord blood albumin had higher risk of development of significant hyperbilirubinemia at the end of 24 and 72 hours. Sahu S et al reported $82.35 \%$ (14/17) neonates developed significant hyperbilirubinemia who had low cord blood albumin level $(<2.8 \mathrm{gm} / \mathrm{dl})$ similarly Kuamr S et al in $90 \%$, Ayyappa GKC in 54.29\% and Trivedi et al in 58.35\% neonates had significant neonatal hyperbilirubinemia with cord albumin level less than $2.8 \mathrm{gm} / \mathrm{dl}$. Cord blood albumin level $<2.8 \mathrm{~g} / \mathrm{dl}$ is high risk factor for future development of neonatal hyperbilirubinemia and Cord blood albumin level $\geq 2.8 \mathrm{~g} / \mathrm{dl}$ is probably safe for early discharge.

Ayyapa GKC et al in their study observed the sensitivity of the cord blood albumin to detect hyperbilirubinemia was $71.8 \%$, while specificity was $65.1 \%$ with positive predictive value $38.9 \%$ and negative predictive value $88.2 \%$. The probability that a neonate with cord blood albumin $<2.8 \mathrm{~g} / \mathrm{dl}$ would later become hyperbilirubinemia was $38.90 \%$ (positive predictive value) similarly Khairy et al, ${ }^{[18]}$ reported cord blood albumin level less than $2.8 \mathrm{gm} / \mathrm{dl}$ had a sensitivity of $85.7 \%$, specificity of $67.3 \%$ with negative predictive value of $96.1 \%$ which in correlation with our study.

\section{Conclusion}

Neonates with cord blood albumin level more than $2.8 \mathrm{gm} / \mathrm{dl}$ can be safely discharged early whereas neonates with albumin levels $<2.8 \mathrm{~g} / \mathrm{dl}$ will need close follow up to check for development of significant jaundice. Hence we recommended that routine estimation of cord blood albumin should be emphasized in all term neonates in institutional delivery. It will help to design and implement the follow up programme in high risk group effectively, and to plan early discharge of babies and mothers.

\section{References}

1. Fok TF. Neonatal jaundice--traditional Chinese medicine approach. J Perinatol 2001; 21 Suppl 1: S98-S100; discussion S104-7

2. Bryon JL, Nancy DS Hyperbilirubinemia in newborn. Pediatrics in Review 2011;32(8):341-9

3. Singhal PK, Singh M, Paul VK, Deorari AK, Ghorpade MG. Spectrum of neonatal hyperbilirubinemia an analysis of 454 cases. Indian Pediatr 1992;29(3)319-25

4. Stark Ann R, Bhutani VK. Chapter 26 Neonatal hyperbilirubinemia. Cloherty and Stark's manual of neonatal care. 8th edition Wolters Kluwer (India) Pvt Ltd New Delhi 2017,335-352

5. Bernaldo AJ, Segre CA. Bilirubin dosage in cord blood: could it predict neonatal hyperbilirubinemia? Sao Paulo Med J. 2004;122(3):99- 103.

6. American Academy of Pediatrics Subcommittee on Hyperbilirubinemia. Management of hyperbilirubinemia in the newborn infant 35 or more weeks of gestation. Pediatrics 2004; 114(1): 297-316.

7. Ballard JL, Khoury JC, Wedig K, Wang L, Eilers-Walsman BL, Lipp R. New Ballard score, expanded to includes extremely premature infants. J Pediatr 1991;119(3):417-23

8. Kramer LI. Advancement of dermal icterus in the jaundiced newborn. Am J Dis Child.1969; 118(3):454-458.

9. Reshad M, Ravichander B, Raghuraman TS. A study cord blood albumin as a predictor of significant neonatal hyperbilirubinemia in term and preterm neonates. Int J Res Med Sci 2016;4(3):887-90

10. Kumar S, Manjunath GA, Ajay J, Reddy S. Low cord serum albumin is a risk indicator in predicting neonatal jaundice. IOSR J Dent Med Sci 2016;15(10):76-8.

11. Gaurav Aiyappa KC, Shriyan A, Raj B. Cord blood albumin as a predictor of neonatal hyperbilirubinemia in healthy neonates. Int $\mathrm{J}$ Contemp Pediatr. 2017;4(2):503-506

12. Sun G, Wang YL, Liang JF, Du LZ. Predictive value of umbilical cord blood bilirubin level for subsequent neonatal jaundice. Zhonghua Er Ke Za Zhi 2007:45: 848-52.

13. Sahu S, Abraham R, John J, Mathew AA, George AS. Cord blood albumin as a predictor of neonatal jaundice. Int J Biol Med Res 2011; 2(1): 436-8.

14. Pradhan A, Lamichaney R, Sharma V. Cord blood bilirubin level as a predictor of development of pathological hyperbilirubinemia in newborns. Int J Contemp Pediatr. 2017;4(4):1519-24.

15. Taksande A, Vilhekar K, Jain M, Zade P, Atkari S, Verkey S. Prediction of the development of neonatal hyperbilirubinemia by increased umbilical cord blood bilirubin. Curr Pediatr Res. 2005;9(1 \& 2):5-9.

16. Randev S, Grover N. Predicting neonatal hyperbilirubinemia using first day serum bilirubin levels. Indian J Pediatr 2010; 77(2): 147- 50.

17. Gupta S, Gupta VK, Bhatnagar JP, Agrawal P, Agarwal A, Bhatia S, et al. Neonatal hyperbilirubinemia after induction of labour with oxytocin and cord serum albumin is compared with cord serum bilirubin as a risk indicator. Int J Biomed Res.2016;7(7):435-438

18. Khairy MA, Abuelhamd WA, Elhawary IM, Mahmoud Nabayel AS. Early predictors of neonatal hyperbilirubinemia in full term newborn. Pediatrics and Neonatology 2018, https://doi.org/10.1016/j.pedneo.2018.07.005 
Copyright: () the author(s), 2019. It is an open-access article distributed under the terms of the Creative Commons Attribution License (CC BY 4.0), which permits authors to retain ownership of the copyright for their content, and allow anyone to download, reuse, reprint, modify, distribute and/or copy the content as long as the original authors and source are cited.

How to cite this article: Meshram RM, Merchant S, Pathan SN. Utility of Cord Blood Albumin as a Predictors of Significant Neonatal Hyperbilirubinemia in Healthy Term Neonate. Asian J. Clin. Pediatr. Neonatol.2019;7(1):17-21.

DOI: dx.doi.org/10.21276/ajcpn.2019.7.1.5

Source of Support: Nil, Conflict of Interest: None declared. 